\title{
A Density Functional Theory Study of the Ionic and Electronic Transport Mechanisms in LiFeBO3 Battery Electrodes
}

\author{
Loftager, Simon; García Lastra, Juan Maria; Vegge, Tejs
}

Published in:

Journal of Physical Chemistry C

Link to article, DOI:

10.1021/acs.jpcc.6b03456

Publication date:

2016

Document Version

Publisher's PDF, also known as Version of record

Link back to DTU Orbit

Citation (APA):

Loftager, S., García Lastra, J. M., \& Vegge, T. (2016). A Density Functional Theory Study of the lonic and Electronic Transport Mechanisms in LiFeBO 3 Battery Electrodes. Journal of Physical Chemistry C, 120(33), 18355-18364. https://doi.org/10.1021/acs.jpce.6b03456

\section{General rights}

Copyright and moral rights for the publications made accessible in the public portal are retained by the authors and/or other copyright owners and it is a condition of accessing publications that users recognise and abide by the legal requirements associated with these rights.

- Users may download and print one copy of any publication from the public portal for the purpose of private study or research.

- You may not further distribute the material or use it for any profit-making activity or commercial gain

- You may freely distribute the URL identifying the publication in the public portal 


\title{
A Density Functional Theory Study of the Ionic and Electronic Transport Mechanisms in $\mathrm{LiFeBO}_{3}$ Battery Electrodes
}

\author{
Simon Loftager, Juan María García-Lastra, and Tejs Vegge* \\ Department of Energy Conversion and Storage, Technical University of Denmark, Fysikvej, 2800 Kgs. Lyngby, Denmark
}

Supporting Information

ABSTRACT: Lithium iron borate is an attractive cathode material for Li-ion batteries due to its high specific capacity and low-cost, earth-abundant constituents. However, experiments have observed poor electrochemical performance due to the formation of an intermediate phase, that is, $\mathrm{Li}_{x} \mathrm{FeBO}_{3}$, which leads to large overvoltages at the beginning of charge. Using a convex-hull analysis, based on Hubbard-corrected density functional theory $(\mathrm{DFT}+U)$, we identify this intermediate phase as $\mathrm{Li}_{0.5} \mathrm{FeBO}_{3}$. Moreover, we show by means of the nudged elastic band (NEB) method, that the origin of these adverse electrochemical effects can be explained by an intrinsically low Li-ion and electron/holepolaron mobility in $\mathrm{Li}_{0.5} \mathrm{FeBO}_{3}$ due to high activation barriers for

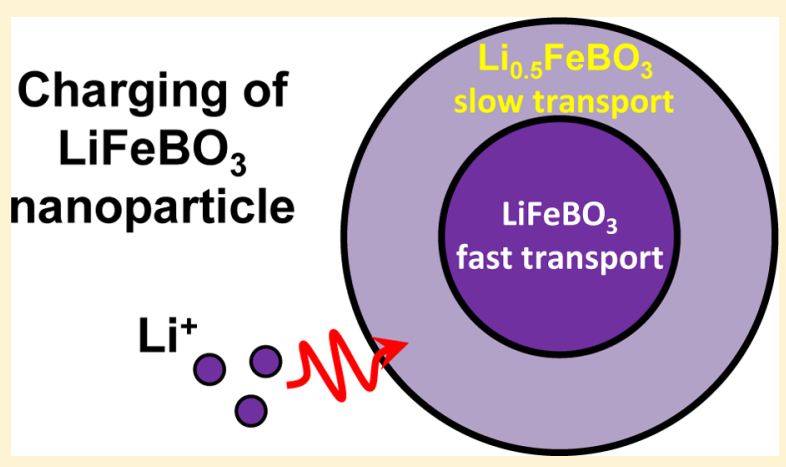
both the ionic and electronic transport. These studies include the effects of the experimentally reported commensurate modulation. We have also investigated the Li-ion/hole diffusion through the interface between $\mathrm{Li}_{0.5} \mathrm{FeBO}_{3}$ and $\mathrm{LiFeBO}_{3}$, which is found not to result in additional kinetic limitations from Li diffusion across the intraparticle interfaces. These findings suggest that the experimentally observed diminished performance associated with the formation of intermediate phases is linked to the intrinsically poor properties of the $\mathrm{Li}_{0.5} \mathrm{FeBO}_{3}$ phase rather than to the presence of interfaces between different phases.

\section{INTRODUCTION}

Lithium-ion batteries (LIBs) are now the dominating energystorage medium for portable electronic devices and may provide an important step toward the improvement of storage of sustainable energy from intermittent sources such as wind, solar, and hydroelectric power in the form of large-scale battery grids enabling load leveling and peak shaving. In addition, LIBs provide the backbone for the growing demand for transportable energy storage in electric vehicles.

The heaviest electroactive component of a battery is the cathode and thus much research has focused on improving upon its energy density and power density. Among the most popular cathode materials is the layered transition-metal oxide, $\mathrm{LiNi}_{1 / 3} \mathrm{Mn}_{1 / 3} \mathrm{Co}_{1 / 3} \mathrm{O}_{2}$ (NMC), which combines a high theoretical capacity of $278 \mathrm{mAh} / \mathrm{g}$ with excellent cyclability ${ }^{1}$ but is limited by the toxicity and high cost of Co. A promising alternative to the layered transition-metal oxides are the transition-metal olivine-structured materials, such as $\mathrm{LiFePO}_{4}$, which consists of earth-abundant, environmentally benign elements. However, $\mathrm{LiFePO}_{4}$ suffers from a low rate capability resulting from low ionic and electronic conductivity, which can only be alleviated by down-sizing the particles of the active material, decreasing their volumetric energy density. Another member of the polyanionic structure class is lithium iron borate, $\mathrm{LiFeBO}_{3}$, which enjoys a high theoretical specific capacity of $220 \mathrm{mAh} / \mathrm{g}$ and displays volume changes shown to be as small as $2 \%$ compared to $6.7 \%$ for the delithiation of
$\mathrm{LiFePO}_{4}{ }^{2}{ }^{2}$ This significantly lowers the risk of the electrode material cracking during $\mathrm{Li}$ insertion and extraction, thereby preventing loss of contact between the active cathode material and current collector, resulting in an increase in the expected lifetime and overall battery performance. However, in many other applications of today's battery systems an important requirement is fast charge and recharge properties. This puts severe restrictions on a number of available cathode materials, because both a low ionic and low electronic mobility will decrease the rate capability and achievable capacity of the cathode. $^{3}$ Because many of the limitations on the rate capability of the cathode materials are caused by issues related to the electronic and ionic transport in the bulk and across external interfaces (e.g., carbon coating on an electrode) and internal interfaces (e.g., the interface between regions with different $\mathrm{Li}$ concentrations), improvements on these properties requires a detailed understanding of the reactions occurring at the interfaces at the atomic level. Such detailed insights can be accessed through advanced computational techniques, where, in particular, density functional theory $(\mathrm{DFT})^{4,5}$ offers a compelling compromise between accuracy and computational cost, for instance, in studies involving fast screening of a wide range of materials properties as compared to conventional

Received: April 5, 2016

Revised: June 22, 2016

Published: July 25, 2016 
a)

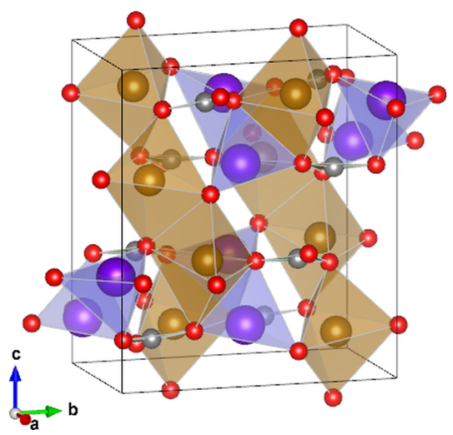

b)

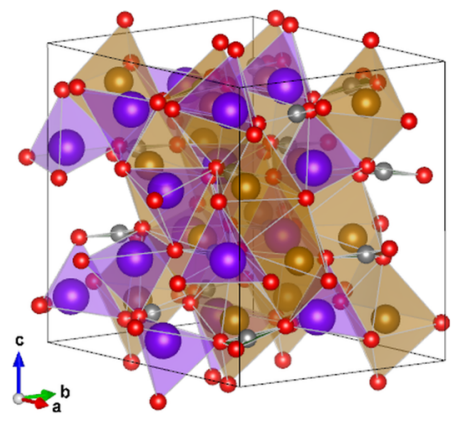

c)

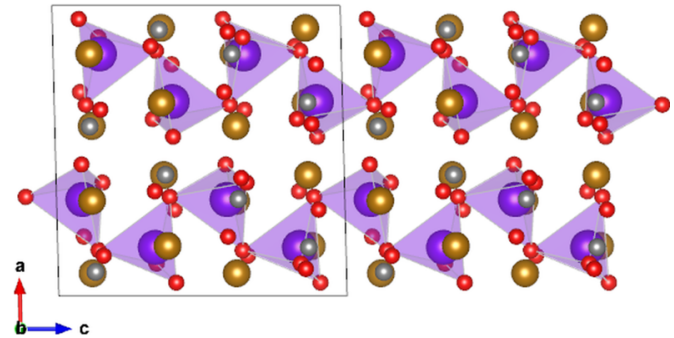

Figure 1. (a) Unit cell of the DFT-optimized unmodulated $\mathrm{LiFeBO}_{3}$ structure showing $\mathrm{Fe}$ atoms in brown residing in brown FeO $\mathrm{D}_{5}$ complexes linked

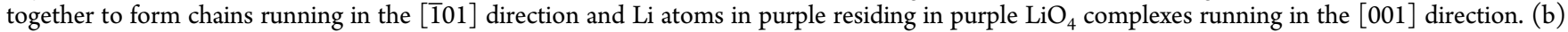
Unit cell of DFT-optimized modulated $\mathrm{LiFeBO}_{3}$ structure. (c) Corner-sharing $\mathrm{LiO}_{4}$ complexes running in the [001] direction in modulated $\mathrm{LiFeBO}_{3}$. Boron atoms are gray and oxygen atoms are red. (Images generated with the VESTA software package. ${ }^{19}$ )

experimental techniques. ${ }^{6}$ Not surprisingly, DFT studies have played a key role in determining the dominating transport mechanisms for $\mathrm{Li}$ ions ( $\mathrm{Li}$ ions at $\mathrm{Li}$-ion lattice sites) and holes (lattice sites where $\mathrm{Li}$ ions have been removed) in lithium transition-metal phosphates ${ }^{7}$ and borates, ${ }^{8}$ as well as for electrons and holes in lithium transition-metal phosphates ${ }^{9}$ and $\mathrm{Li}-$ air batteries. ${ }^{10-12}$

In general, the formation of interfaces during charge/ discharge has a large impact on electrochemical properties, such as rate capability, achievable capacity and voltage. In the case of $\mathrm{LiFePO}_{4}$, the (de)lithiation mechanism in $\mathrm{LiFePO}_{4}$ has been suggested to proceed via a two-phase reaction between the endmembers, $\mathrm{Li}_{0.98} \mathrm{FePO}_{4}$ and $\mathrm{Li}_{0.02} \mathrm{FePO}_{4}{ }^{13}$ Because $\mathrm{LiFePO}_{4}$ and $\mathrm{LiFeBO}_{3}$ both have been shown to have their $\mathrm{Li}$ diffusion confined to channels ${ }^{8,14}$ (along the $b$-axis in $\mathrm{LiFePO}_{4}$ and along the $c$-axis in $\mathrm{LiFeBO}_{3}$ ), a natural question is whether the two compounds share the same (de)intercalation mechanism, that is, whether the (de)lithiation of $\mathrm{LiFeBO}_{3}$ proceeds via a two-phase reaction. Galvanostatic intermittent titration technique (GITT) experiments on carbon-coated $\mathrm{LiFeBO}_{3}$ nanoparticles performed by Yamada et al. ${ }^{2}$ have revealed a continuous shift of diffraction peaks in the lattice parameters and a sloping OCV curve of $\mathrm{Li}_{x} \mathrm{FeBO}_{3}$, indicating a solid-solution-type behavior in the approximate Li-concentration range of $0.15 \leq x \leq 0.5$ (that is, during the initial stage of discharge). Their GITT experiments and DFT studies suggested that in the Li-concentration range $0.5 \leq x \leq 1.0$ one or more two-phase reactions occurred, which was unambiguously corroborated by Bo et al., ${ }^{15}$ who later reported indications of the existence of a stable interface between regions of $\mathrm{LiFeBO}_{3}$ and $\mathrm{Li}_{0.5} \mathrm{FeBO}_{3}$ phases. ${ }^{16}$

Here, we first present a thermodynamic stability analysis of the possible compounds between the compositions $\mathrm{FeBO}_{3}$ and $\mathrm{LiFeBO}_{3}$, which reveals a stable intermediate phase at half lithiation, that is, at $\mathrm{Li}_{0.5} \mathrm{FeBO}_{3}$. Second, the diffusion barriers of $\mathrm{Li}$ ions in $\mathrm{FeBO}_{3}$, $\mathrm{Li}$ holes in $\mathrm{LiFeBO}_{3}$, and $\mathrm{Li}$ ions in the most stable configuration of $\mathrm{Li}_{0.5} \mathrm{FeBO}_{3}$ are calculated and a significant lowering of the diffusivity in $\mathrm{Li}_{0.5} \mathrm{FeBO}_{3}$, as compared to the diffusivities in $\mathrm{LiFeBO}_{3} / \mathrm{FeBO}_{3}$, is predicted to take place.

Internal interfaces that may form during the initial-stage delithiation are also investigated and the $\mathrm{Li}$-defect diffusion across the interfaces themselves is determined not to lower the overall $\mathrm{Li}$ transport in $\mathrm{LiFeBO}_{3}$. Seo et al. ${ }^{8}$ calculated a $3.19 \mathrm{eV}$ bandgap in $\mathrm{LiFeBO}_{3}$, which is large enough to prevent the thermal activation of electrons or holes, and ascribed the electronic conduction to electron and hole polarons, that is, states where the excess charge is carried by a local distortion of the lattice. We prove the existence of these electron and hole polarons localizing on $\mathrm{Fe}$ ions and furthermore, the hopping mechanisms of these polarons in relevant phases of bulk $\mathrm{Li}_{x} \mathrm{FeBO}_{3}$ are investigated and we show that the most stable $\mathrm{Li}$ configuration in $\mathrm{Li}_{0.5} \mathrm{FeBO}_{3}$ lowers the electronic mobility relative to both $\mathrm{LiFeBO}_{3}$ and $\mathrm{FeBO}_{3}$. These findings strongly suggest that the $\mathrm{Li}(\mathrm{de})$ intercalation in $\mathrm{LiFeBO}_{3}$ is intrinsically impeded by the transport of $\mathrm{Li}$ ions and electron/hole polarons, in particular in the $\mathrm{Li}_{0.5} \mathrm{FeBO}_{3}$ phase.

\section{METHODOLOGY}

2.1. The Crystal Structure of $\mathrm{LiFeBO}_{3}$. Early experimental reports ${ }^{17}$ showed that lithium iron borate $\left(\mathrm{LiFeBO}_{3}\right)$ has a monoclinic crystal symmetry in which chains of edge-sharing $\mathrm{FeO}_{5}$ trigonal bipyramids align along the [101] direction, and chains of $\mathrm{LiO}_{4}$ tetrahedra in pairs run along the [001] direction with planar $\mathrm{BO}_{3}$ groups connecting the edge-sharing $\mathrm{FeO}_{5}$ chains. The DFT-optimized geometry of this structure is shown in Figure 1. X-ray diffraction studies by Janssen et al. ${ }^{18}$ revealed that a commensurately modulated superstructure exists in $\mathrm{LiFeBO}_{3}$, which effectively doubles the unit cell along the $a$-axis and displaces the $\mathrm{Li}$ ions out of the trigonal bipyramidal equatorial planes toward the center of the four neighboring $\mathrm{O}$ ions and altering the crystal symmetry from $C 2 / c$ to $C 2 /$ $c(\alpha 0 \gamma) 00$ with $\alpha=1 / 2$ and $\gamma=0$. Following Janssen et al., ${ }^{18}$ the modulation of $\mathrm{LiFeBO}_{3}$ giving rise to the $C 2 / c(\alpha 0 \gamma) 00$ crystal symmetry was also modeled here in a $P 2_{1} / c$ crystal symmetry, and the lattice parameters and atomic positions used as a starting point for our structure optimizations of the modulated $\mathrm{LiFeBO}_{3}$ were those in Table $\mathrm{S} 7$ reported by Janssen et al.: ${ }^{18} a$ $=10.3469 \AA, b=8.9209 \AA, c=10.2528 \AA$, and $\beta=90.878^{\circ}$. In order to assess the stability of the modulated (as modeled in the $P 2_{1} / c$ symmetry) versus unmodulated (C2/c symmetry) $\mathrm{LiFeBO}_{3}$, calculations on unmodulated $\mathrm{LiFeBO}_{3}$ were started with the lattice parameters reported by Janssen et al.: ${ }^{18} a=$ $5.1350 \AA, b=9.0437 \AA, c=10.2907 \AA, \beta=91.031^{\circ}$. Upon Li extraction (charge) of $\mathrm{LiFeBO}_{3}$ the oxidation occurs on the $\mathrm{Fe}^{2+}$ ions, which become $\mathrm{Fe}^{3+}$ ions. The $\mathrm{Fe}$ ions are always determined to be in their high-spin state. Therefore, $\mathrm{Fe}$ in $\mathrm{LiFeBO}_{3}$ is $\mathrm{Fe}^{2+}$ and $\mathrm{Fe}$ in $\mathrm{FeBO}_{3}$ is $\mathrm{Fe}^{3+}$, possessing a magnetic moment of 4 and $5 \mu_{\mathrm{B}}$, respectively.

2.2. Computational Methods. In this study, all structures were set up and analyzed using the Atomic Simulation Environment (ASE) package ${ }^{20}$ and relaxed to their ground 
state by solving the electronic-structure problem within DFT. The Vienna Ab initio Simulation Package (VASP) ${ }^{21}$ was used in which plane waves were expanded up to a kinetic-energy cutoff of $500 \mathrm{eV}$ and the projector-augmented-wave (PAW) method $^{22}$ was employed to describe the atomic cores. In the PAW pseudopotentials, for $\mathrm{Li}, \mathrm{B}$, and $\mathrm{O}$ the 1 s electrons were treated as core electrons and for Fe the electrons up to $3 p$ (including $3 \mathrm{p}$ ) were treated as core electrons. The exchangecorrelation effects were described within the generalizedgradient approximation (GGA) by the Perdew-BurkeErnzerhof (PBE) functional. ${ }^{23}$ For the determination of the partial occupancies, the tetrahedron method with Blöchl corrections ${ }^{24}$ were used and the electronic levels were smeared by $0.05 \mathrm{eV}$.

The incomplete cancellation of the electronic self-interaction in the GGA often leads to significant deviations from experimental results, in particular the band gap, ${ }^{25,26}$ which are due to the propensity of the self-interaction toward delocalizing the electrons, in particular for systems exhibiting a strong localization of the d-orbital electrons, as is the case of $\mathrm{LiFeBO}_{3}$. This problem has previously ${ }^{2,8}$ been alleviated by employing the Hubbard- $U$ correction $^{27}$ and following Seo et al., ${ }^{8}$ a value of $U=4.3 \mathrm{eV}$ was therefore applied on the $3 \mathrm{~d}$ orbitals of $\mathrm{Fe}$ in $\mathrm{Li}_{x} \mathrm{FeBO}_{3}$.

Three kinds of simulation cells were used. For the structural relaxation of the unit cell of $\mathrm{LiFeBO}_{3}$, the $k$-point sampling was performed using a Monkhorst-Pack ${ }^{28}(\mathrm{MP})$ mesh of $4 \times 2 \times$ 2 , for the $(2 a, b, c)$ supercells a MP mesh of $2 \times 2 \times 2$ was used and for the $(a, b, 2 c)$ supercells a $4 \times 2 \times 1 \mathrm{MP}$ mesh was used. Structures were relaxed until all forces did not exceed $0.05 \mathrm{eV} /$ A using the FIRE minimization algorithm. ${ }^{29}$ The self-consistent solution to the Kohn-Sham equation was performed with an accuracy of $0.1 \mathrm{meV}$.

In our model, an electron (hole) polaron was simulated by adding (removing) an electron (hole) to the $\mathrm{FeBO}_{3}\left(\mathrm{LiFeBO}_{3}\right)$ supercell having a compensating background charge in order to maintain charge neutrality. The symmetry of the system was broken by stretching (compressing) the $\mathrm{Fe}-\mathrm{O}$ bonds for a particular $\mathrm{Fe}$ ion in the unit cell, around which the electron (hole) is expected to be localized. This approach enabled charge localization and lowered the computation time of the structural relaxations.

In order to determine the activation barriers of the Li-ion/ hole jumps and polaron hops, the nudged elastic band (NEB) method $^{30}$ as implemented in ASE was employed with a total number of seven images, where the initial particle trajectory was created by linearly interpolating between the initial and final image. The energies and forces were calculated by VASP, and the forces were let to relax to the same threshold as for the structure relaxations $(0.05 \mathrm{eV} / \AA)$.

\section{RESULTS AND DISCUSSION}

3.1. Optimized Lattice of $\mathrm{LiFeBO}_{3}$. Our DFT calculations on modulated $\mathrm{LiFeBO}_{3}$ yields the optimized lattice parameters $a=10.409 \AA, b=8.9953 \AA, c=10.324 \AA$, and $\beta=91.39^{\circ}$, and for unmodulated $\mathrm{LiFeBO}_{3}$ the lattice parameters relaxed to $a=$ 5.1683, $b=9.1086 \AA, c=10.3485 \AA$, and $\beta=91.283^{\circ}$. The DFT calculations also reveal that the modulated phase of $\mathrm{LiFeBO}_{3}$ is more stable than the unmodulated phase by 11 $\mathrm{meV} /$ f.u., agreeing well with the stability energy reported by Janssen et al. ${ }^{18}$ of $12 \mathrm{meV} /$ f.u. Both sets of lattice parameters are in good agreement with experimental values ${ }^{18}$ (vide supra). As Janssen et al. ${ }^{18}$ report, we find that the length of the apical
$\mathrm{Li}-\mathrm{O}$ bond (along the $c$-axis) in the $\mathrm{LiO}_{4}$ tetrahedra is longer than the other $\mathrm{Li}-\mathrm{O}$ bonds by approximately $0.1 \AA$ in modulated $\mathrm{LiFeBO}_{3}$. Upon full delithiation yielding $\mathrm{FeBO}_{3}$, the lattice parameters relaxed to $a=5.3078 \AA, b=8.9894 \AA, c=$ $10.1876 \AA$, and $\beta=89.399^{\circ}$ resulting in a volume change from modulated $\mathrm{LiFeBO}_{3}$ to $\mathrm{FeBO} 3$ of $0.6 \%$.

3.2. Thermodynamics of Bulk $\mathrm{Li}_{x} \mathrm{FeBO}_{3}$. Experimental and computational results by Yamada et al. ${ }^{2}$ and Bo et al. ${ }^{16}$ suggest the possible existence of partially lithiated phases. Using the convex-hull method, ${ }^{26}$ the phase stability of $\mathrm{Li}_{x} \mathrm{FeBO}_{3}$ at different $\mathrm{Li}$ concentrations were analyzed. In this method, the relative energy per formula unit at a given $\mathrm{Li}$ concentration, $x$, is given by

$$
E_{\text {rel }}(x) \equiv E_{\mathrm{Li}_{x} \mathrm{FeBO}_{3}}-x E_{\mathrm{LiFeBO}_{3}}-(1-x) E_{\mathrm{FeBO}_{3}}
$$

where $E_{\mathrm{Li}_{x} \mathrm{FeBO}_{3}}$ is the total energy obtained from DFT calculations for the respective structure per formula unit. The convex hull is constructed by connecting the most stable phases of the compound while ensuring that the curvature of the resulting curve is always positive. If the relative energy at a specific Li concentration is higher than the energy of the line joining the lowest-energy configurations at the neighboring $\mathrm{Li}$ concentrations (that is, the convex hull), the corresponding phase is unstable relative to a blend of the phases at the neighboring Li concentrations. This scenario would correspond to a two-phase reaction and would result in a plateau in the voltage profile. For the construction of the convex hull of $\mathrm{Li}_{x} \mathrm{FeBO}_{3}$, all symmetry-inequivalent $\mathrm{Li}$ arrangements in the unit cell of unmodulated $\mathrm{Li}_{x} \mathrm{FeBO}_{3}$ were investigated: for $x=$ $\{0,1 / 8,7 / 8,1\}, 1$ combination exists, for $x=\{1 / 4,3 / 8,5 / 8,3 /$ 4\}, 7 combinations exist, and for $x=1 / 2,14$ combinations exist. These structures were then doubled in the $a$-direction, so as to resemble the size of the unit cell of modulated $\mathrm{LiFeBO}_{3}$, and fully relaxed. Naturally, the energy of the $a$-doubled unmodulated structures was twice the energy of the unmodulated unit-cell structure. The relative energies are shown in Figure $2 \mathrm{a}$ as black circles. Also, the $\mathrm{Li}$ configurations found in the unmodulated $\mathrm{Li}_{x} \mathrm{FeBO}_{3}$ structures were calculated with the modulation included, and these are shown in Figure 2a as black plusses. In order to extend the phase-stability model to include possible clustering of $\mathrm{Li}$ ions and holes, supercells were created by repeating the unit cell of unmodulated $\mathrm{Li}_{x} \mathrm{FeBO}_{3}$ in the $a$-direction. The selected $\mathrm{Li}$ configurations in these supercells were determined as those minimizing or maximizing the Coulomb repulsion between the $\mathrm{Li}$ ions, yielding an additional 14 structures (that is, two different structures for the seven intermediate configurations). The relative energies obtained from the supercell configurations of unmodulated $\mathrm{Li}_{x} \mathrm{FeBO}_{3}$ are included as red circles. Additionally, the $\mathrm{Li}$ configurations found in unmodulated $\mathrm{Li}_{x} \mathrm{FeBO}_{3}$ structures maximizing/minimizing the Coulomb repulsion were calculated with the modulation included, and these are shown in Figure 2a as red plusses. Figure $2 \mathrm{~b}$ shows the profile for the open-circuit voltage $(\mathrm{OCV})$ calculated by

$$
U_{\mathrm{OCV}}(x)=-\frac{E_{\mathrm{Li}_{x_{2}} \mathrm{FeBO}_{3}}-E_{\mathrm{Li}_{x_{1}} \mathrm{FeBO}_{3}}-\left(x_{2}-x_{1}\right) E_{\mathrm{Li}(s)}}{\left(x_{2}-x_{1}\right) e}, \quad x_{1}<x<x_{2}
$$

where the energies, $E_{\mathrm{Li}_{x} \mathrm{FeBO}_{3}}$, are calculated using DFT and $E_{\mathrm{Li}(\mathrm{s})}$ indicates that all voltages are calculated with respect to the $\mathrm{Li}$ metal electrode. 
a)

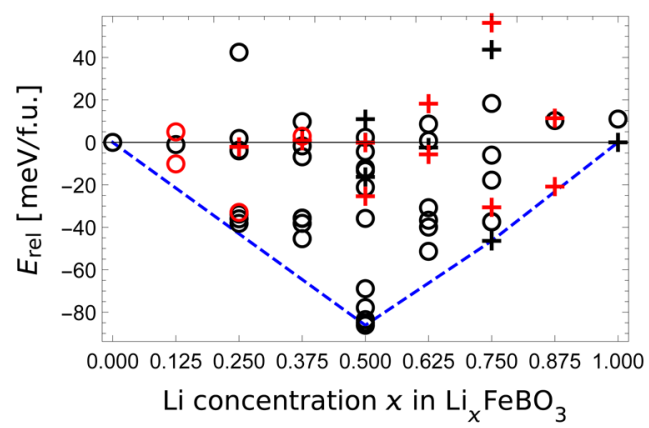

O Unmodulated, symmetry-inequivalent structures

○ Unmodulated structures predicted to extremize Coulomb repulsion

+ Modulated, symmetry-inequivalent structures

+ Modulated structures predicted to extremize Coulomb repulsion

b)

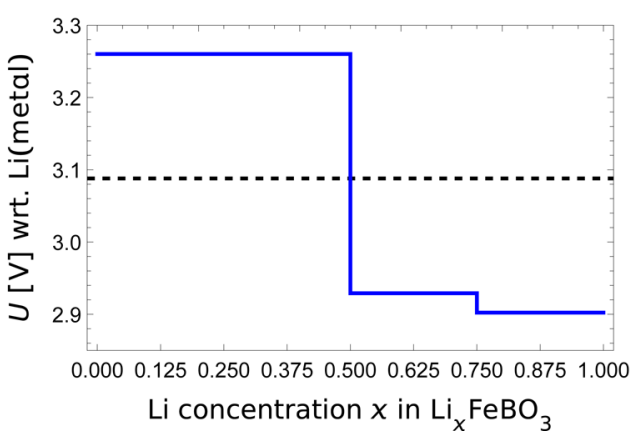

Figure 2. (a) The convex-hull construction showing relative energies for all possible $\mathrm{Li}$ configurations in a unit cell of $\mathrm{Li}_{x} \mathrm{FeBO}_{3}$, calculated in a $a$-doubled cell, indicated by black markers (circle, unmodulated structure; cross, modulated structure), and $a$-doubled structures minimizing or maximizing the Coulomb repulsion, indicated by red markers, calculated by eq 1 . The convex hull is indicated by the blue dashed line. (b) The voltage profile calculated by eq 2 using the convex-hull energies in (a) is shown as a blue line and the equilibrium potential, $U_{\text {eq }}=\frac{E_{\mathrm{LiFeBO}_{3}}-\left(E_{\mathrm{FeBO}_{3}}+16 E_{\mathrm{Li}(\mathrm{s} s}\right)}{16 e}$, is shown as a black dashed line.

The convex-hull construction in Figure 2a shows that the lowest-energy $\mathrm{Li}$ configuration for the phases having $\mathrm{Li}$ concentration of $x=0.0,0.25,0.375,0.5$, and 0.625 is obtained from an $a$-doubled unit-cell structure. In the case of $x=0.125$, the lowest-energy $\mathrm{Li}$ configuration is obtained from an unmodulated unit-cell structure doubled in the a-direction, whereas for $x=0.875$, the lowest-energy $\mathrm{Li}$ configuration is obtained from a modulated structure, though in both cases the $\mathrm{Li}$ ions are distributed such that the Coulomb repulsion between the $\mathrm{Li}$ ions is minimized. At the latter concentration, the modulated symmetry-inequivalent structure relaxes to that of the unmodulated one. It is also noteworthy, that it is primarily for Li concentrations of $x>0.5$ where the modulated structure is more stable than the unmodulated structure having the same Li distribution. This tallies well with the suggestion of Bo et al. ${ }^{16}$ that the modulation is lost in the delithiated phase and in other Li-deficient phases. The half-lithiated phase, $\mathrm{Li}_{0.5} \mathrm{FeBO}_{3}$, has the highest stability relative to the other calculated phases. The $\mathrm{Li}_{0.75} \mathrm{FeBO}_{3}$ phase predicted to be stable by Yamada et al. ${ }^{2}$ is also predicted to be stable in our model, whereas the phase at $\mathrm{Li}_{0.875} \mathrm{FeBO}_{3}$ is not. This is reflected in the voltage profile in Figure $2 \mathrm{~b}$, where three plateaus are seen, one at $3.26 \mathrm{~V}$ for $0.0<x<0.5$, one at $2.93 \mathrm{~V}$ for $0.5<x<0.75$, and one at $2.90 \mathrm{~V}$ for $0.75<x<1.0$ together with an equilibrium voltage of $3.08 \mathrm{~V}$ (dashed line), which compares well with experimental values of about $3.0 \mathrm{~V}^{2}$ The bending of the convex hull due to the stable phase at $x=0.75$ results in a plateau splitting of $0.05 \mathrm{~V}$ between the voltage plateaus at $0.5<x<$ 0.75 and $0.75<x<1.0$, a voltage difference that is likely to be detectable only in very slow GITT experiments.

The crystal structure of the lowest-energy configuration in the half-lithiated phase is shown in Figure 3 and the positions of the $\mathrm{Li}$ ions in the lowest-energy Li configuration are given in Table S1 in Supporting Information. In this configuration, the unmodulated phase is favored above the modulated phase. It can be seen that the lowest-energy configuration of $\mathrm{Li}_{0.5} \mathrm{FeBO}_{3}$ favors a pairwise arrangement in which $\mathrm{Li}$ ions reside relatively close to each other $(3.4 \AA)$ in pairs with the $z$ component of the center-of-mass position of these pairs alternating along the $b$ direction. Intuitively, one would expect the $\mathrm{Fe}^{2+}$ ions to be closest to the $\mathrm{Li}^{+}$ions, thereby minimizing the Coulomb repulsion between the $\mathrm{Fe}$ ions and the $\mathrm{Li}$ ions. This is indeed the case for the extreme phases, that is, $\mathrm{LiFeBO}_{3}$ containing one $\mathrm{Li}$ hole and $\mathrm{FeBO}_{3}$ containing on $\mathrm{Li}$ ion. Interestingly, this is not the case for the most stable $\mathrm{Li}$ configuration of the halflithiated phase, as the actual $\mathrm{Fe}^{2+} / \mathrm{Fe}^{3+}$-ion distribution in this phase is $61 \mathrm{meV} /$ f.u. more stable than the $\mathrm{Fe}^{2+} / \mathrm{Fe}^{3+}$-ion distribution predicted to be the most stable by a model minimizing the Coulombic repulsion created by the $\mathrm{Li}^{+}$ions at the Fe sites. This suggests that the elastic relaxations of the lattice after adding or removing $\mathrm{Li}^{+}$ions and the $\mathrm{Fe}-\mathrm{Fe}$-ion interactions (electrostatic and magnetic) could play an important role in the stabilization of particular $\mathrm{Fe}^{2+} / \mathrm{Fe}^{3+}$-ion arrangements. The same analysis applied to the second, third, and fourth most stable configuration of the $\mathrm{Li}_{0.5} \mathrm{FeBO}_{3}$ phase shows that the most favorable $\mathrm{Fe}^{2+} / \mathrm{Fe}^{3+}$-ion distribution is the one predicted by only including the effects of the Coulombic potential created by the $\mathrm{Li}^{+}$ions at the $\mathrm{Fe}$ sites. The more complex $\mathrm{Fe}^{2+} / \mathrm{Fe}^{3+}$-ion ordering in the lowest-energy halflithiated phase is expected to yield a more complex energy landscape of Li-ion diffusion as compared to the active endmembers, in particular at low C-rates, where the equilibrium structure is expected to form. However, for real materials synthesized at room temperature entropic and kinetic effects result in the actual structure containing several of the lowest-energy configurations. Nevertheless, the transport properties of this phase are expected to be representative for the defect configuration.

All intermediate points in the range $0.0<x<0.5$ reside above the convex hull in Figure 2a, suggesting that a two-phase reaction could occur in this region, possibly forming a stable $\mathrm{Li}_{0.5} \mathrm{FeBO}_{3}-\mathrm{FeBO}_{3}$ interface during low-C-rate operation in which each phase has had sufficient time to reach its most stable Li configuration. However, this is not the case for the range $0.5<x<1.0$, where the lowest-energy configuration at $x$ $=0.75$ resides $3.3 \mathrm{meV} /$ f.u. below a line connecting the lowestenergy configurations of the $\mathrm{Li}_{0.5} \mathrm{FeBO}_{3}$ phase and the $\mathrm{LiFeBO}_{3}$ phase. This value is well below the typical accuracy of a DFT calculation, and it is therefore not possible to state with absolute certainty that the lowest-energy point at $x=0.75$ lies below a line connecting the lowest-energy phases at $x=0.5$ and $x=1.0$, that is, that the $\mathrm{Li}_{0.75} \mathrm{FeBO}_{3}$ phase is in fact stable. Additionally, even if the $\mathrm{Li}_{0.75} \mathrm{FeBO}_{3}$ phase was stable, kinetic effects during electrode operation might prevent this phase from reaching its lowest-energy configuration. This scenario 
a)

c)

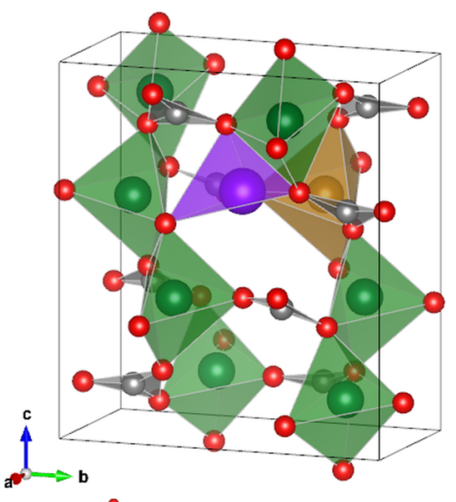

b)

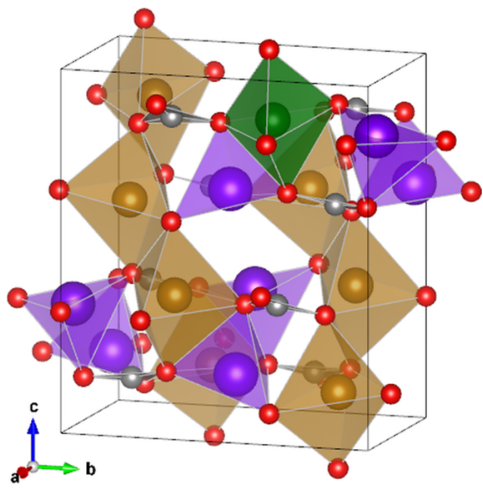

d)

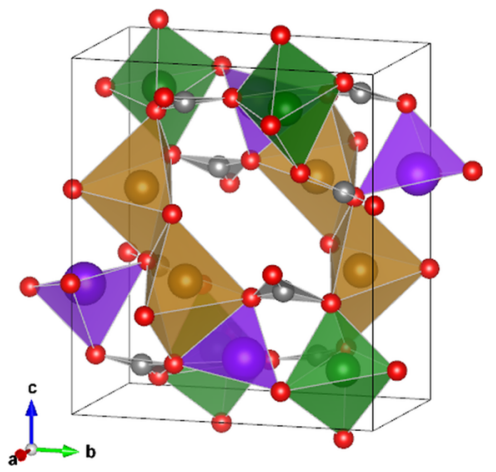

Figure 3. (a) $\mathrm{FeBO}_{3}$ unit cell containing one $\mathrm{Li}$ ion. The brown atoms residing in brown polyhedra are $\mathrm{Fe}^{2+}$ and the green atoms residing in green polyhedra are $\mathrm{Fe}^{3+}$. (b) $\mathrm{LiFeBO}_{3}$ unit cell containing one $\mathrm{Li}$ hole. (c) Structure of the most stable configuration of $\mathrm{Li}_{0.5} \mathrm{FeBO}_{3}$ with the unit cell indicated by the black box. The brown atoms residing in brown polyhedra are $\mathrm{Fe}^{2+}$ on which hole polarons can hop between, and the green atoms residing in green polyhedra are $\mathrm{Fe}^{3+}$ on which the electron polarons can hop between (polaronic transport is investigated in Section 3.6). The polaron-hopping paths $A_{e}-B_{e}-C_{e}-D_{e}-A^{\prime}{ }_{e}$ and $A_{h}-B_{h}-C_{h}-D_{h}-A_{h}^{\prime}$ constitute the paths with the lowest barriers required to move electrons and holes, respectively, in the $c$-direction, where $A_{e}, B_{e}, C_{e}, D_{e}$, and $A^{\prime}{ }_{e}$ denote $F^{3+}$ sites and $A_{h}, B_{h}, C_{h}, D_{h}$, and $A_{h}^{\prime}$ denote Fe ${ }^{2+}$ sites. The positions of the Li ions in this configuration are given in Table S1 in Supporting Information. (d) Unit cell of the half-lithiated phase with the Li-ion configuration of the lowest-energy configuration, but with the $\mathrm{Fe}^{2+} / \mathrm{Fe}^{3+}$-ion distribution predicted by the Coulombic model mentioned in the main text. (Images generated with the VESTA software package. ${ }^{19}$ ).

would correspond to the formation of a stable interface between $\mathrm{Li}_{0.5} \mathrm{FeBO}_{3}$ and $\mathrm{LiFeBO}$ during low-C-rate operation. Experiments performed at $\mathrm{C} / 20$ by Yamada et al. ${ }^{2}$ and at $\mathrm{C} / 30$ and $\mathrm{C} / 50$ by Bo et al. ${ }^{15,16}$ show that a two-phase reaction occurs between the half-lithiated phase and the fully lithiated phase (that is, for $0.5<x<1.0$ ), and our phase-stability analysis indicates that a two-phase region between $\mathrm{LiFeBO}_{3}$ and $\mathrm{Li}_{0.5} \mathrm{FeBO}_{3}$ could indeed be facilely formed and a further analysis of the role of the $\mathrm{Li}_{0.5} \mathrm{FeBO}_{3}$ phase is therefore undertaken.

3.3. Ionic Transport in Modulated $\mathrm{LiFeBO}_{3}$ and $\mathrm{FeBO}_{3}$. In order to determine the influence of the stable half-lithiated phase on the transport properties, NEB calculations were first performed on the modulated, lithiated phase, yielding activation barriers for a Li-hole jump in modulated $\mathrm{LiFeBO}_{3}$, and on the fully delithiated phase, yielding activation barriers for Li-ions jumps in $\mathrm{FeBO}_{3}$; the resulting activation barriers are shown in Figure 4. For transport along the $a$-axis, the motion of $\mathrm{Li}$ ions and Li holes occurs occurs by a jump of $2.49 \AA$, henceforth referred to as A (following the jump notation of Seo et al. ${ }^{8}$ ), with an activation barrier of 0.29 and $0.40 \mathrm{eV}$ for the $\mathrm{Li}$ ion and hole, respectively, followed by a 4.06- $\AA$ jump out of the $\mathrm{LiO}_{4}$ chain, henceforth referred to as $\mathrm{C}$, with an activation barrier of $1.85 \mathrm{eV}$ for the $\mathrm{Li}$ ion. The same jump for a Li hole has a barrier of $1.74 \mathrm{eV}$, however, it is easier for the Li hole at site $\mathrm{X}$ in Figure $4 \mathrm{~b}$ to move in the $a$-direction by performing $\mathrm{D}$ jumps (instead of C jumps) with barrier of only $1.16 \mathrm{eV}$. The C (D) jump mechanism also constitutes the lowest-energy pathway in which the Li ions (holes) can jump in order to move between the corner-sharing $\mathrm{LiO}_{4}$ chains shown in Figure $4 \mathrm{~b}$. For $\mathrm{Li}$ transport along the $b$-axis, $\mathrm{Li}$ ions/holes are required to make a $5 \AA$ jump, which would result in a prohibitively high activation barrier, effectively making this transport mechanism inactive. For ionic transport along the $c$-axis, the $\mathrm{Li}$ ions and holes have to overcome two barriers: An A jump (2.49 $\AA$ for $\mathrm{Li}$ ions and $3.10 \AA$ for Li holes) with an activation barrier of $0.29 \mathrm{eV}$ for the $\mathrm{Li}$ ions and $0.40 \mathrm{eV}$ for the Li holes, and a jump of $3.58 \AA$ for $\mathrm{Li}$ ions and $3.00 \AA$ for $\mathrm{Li}$ holes, henceforth referred to as $\mathrm{B}$ (following the jump notation of Seo et al. ${ }^{8}$ ), with an activation barrier of $0.75 \mathrm{eV}$ for $\mathrm{Li}$ ions and $0.61 \mathrm{eV}$ for the Li holes. It is interesting to note that $\mathrm{Li}$ at site $\mathrm{X}$ changes position from tetrahedron $T_{1}$ (see Figure $4 b$ ) to $T_{2}$ (see Figure $4 a$ ) upon full delithiation while at the same time increasing the $B$ jump length and decreasing the A jump length. This is also reflected in the activation barriers for Li-ion diffusion as the $\mathrm{B}$ barrier is more than twice the magnitude of the A barrier. The paths with their corresponding activation-barrier profiles are shown in Figure 4 and jump lengths, activation barriers, and diffusivities are listed in Table 1. Additionally, we have calculated activation barriers for Li-hole diffusion in the unmodulated phase shown in Figure S1. However, the barriers do not change significantly compared to the modulated phase of $\mathrm{LiFeBO}_{3}$.

A previous study by Seo et al. ${ }^{8}$ found lower Li-hole barriers of $0.223 \mathrm{eV}$ for the $\mathrm{A}$ jump and $0.437 \mathrm{eV}$ for the $\mathrm{B}$ jump that correspond to a Li-hole diffusivity of about $3.7 \times 10^{-10} \mathrm{~cm}^{2} / \mathrm{s}$ (here using a prefactor of $\nu=10^{-13} \mathrm{~s}^{-1}$ ). The apparent 
a)

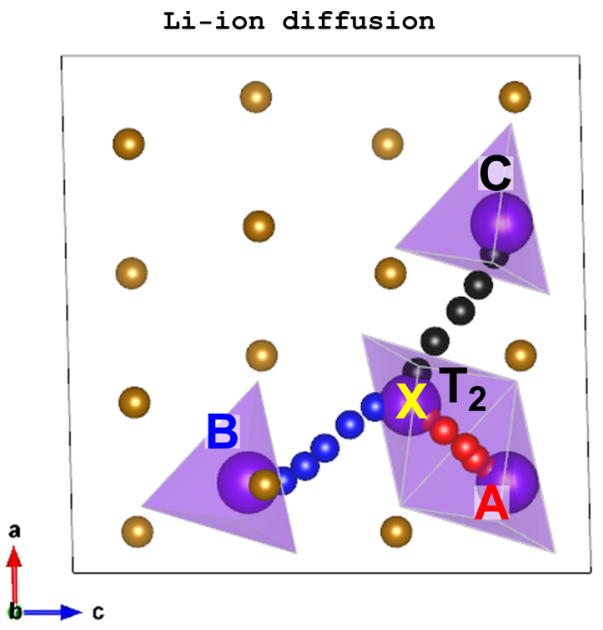

b)

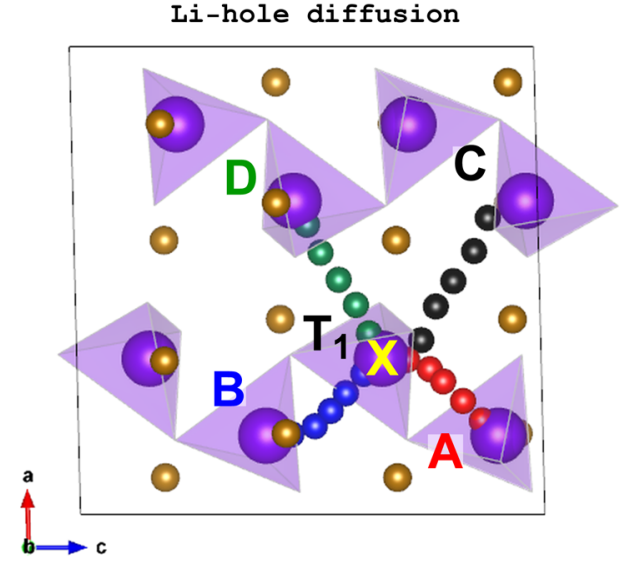

c)

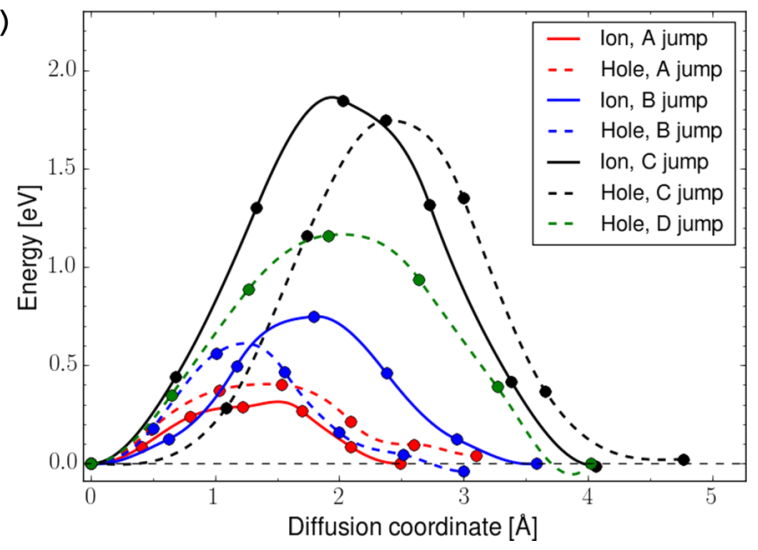

Figure 4. (a) Investigated Li-ion and Li-hole jumps in $\mathrm{FeBO}_{3}$, (b) modulated $\mathrm{LiFeBO}_{3}$, and (c) corresponding activation barriers. The most probable jumps for the $\mathrm{Li}$ ions and $\mathrm{Li}$ holes in the $\mathrm{LiO}_{4}$ chains are $\mathrm{A}$ and $\mathrm{B}$. Purple atoms are $\mathrm{Li}$ residing in purple polyhedra and brown atoms are $\mathrm{Fe}$. The calculations were performed in a $(2 a, b, c)$ supercell. (Images in (a) and (b) generated with the VESTA software package. $\left.{ }^{19}\right)$

discrepancy between these barriers and our barriers most likely originates from the way the strongly correlated $3 \mathrm{~d}$ electrons of $\mathrm{Fe}$ are described within the model. Seo et al. ${ }^{8}$ applied a standard GGA approach, which is known to lack the correct description of the strongly localized d orbitals. To improve upon the description of the strongly localized orbitals of the $\mathrm{Fe}$ atoms, higher-level methods such as the $+U$ correction (applied here) or hybrid functionals are often employed. However, it
Table 1. Jump Lengths, Activation Barriers, and the Corresponding One-Dimensional Diffusional Constants for Li Transport in the $c$-Direction ${ }^{a}$

\begin{tabular}{|c|c|c|c|c|c|}
\hline & & $\begin{array}{c}\text { jump } \\
\text { length, } \\
l[\AA]\end{array}$ & $\begin{array}{c}\text { activation } \\
\text { barrier, } \\
E_{\text {act }}[\mathrm{eV}]\end{array}$ & $\begin{array}{c}\text { DFT- } \\
\text { calculated } \\
\text { room- } \\
\text { temperature } \\
\text { diffusivity, } D \\
{\left[\mathrm{~cm}^{2} / \mathrm{s}\right]}\end{array}$ & $\begin{array}{c}\text { experimental } \\
\text { diffusivity } \\
{\left[\mathrm{cm}^{2} / \mathrm{s}\right]}\end{array}$ \\
\hline \multirow{3}{*}{$\begin{array}{c}\mathrm{Li} \text { ion in } \\
\mathrm{FeBO}_{3}\end{array}$} & A & 2.49 & 0.29 & \multirow[t]{3}{*}{$5.6 \times 10^{-15}$} & \multirow[t]{3}{*}{$5.63 \times 10^{-14 b}$} \\
\hline & $\mathrm{B}$ & 3.58 & 0.75 & & \\
\hline & $\mathrm{C}$ & 4.06 & 1.85 & & \\
\hline \multirow{4}{*}{$\begin{array}{l}\mathrm{Li} \text { hole in } \\
\text { modulated } \\
\mathrm{LiFeBO}_{3}\end{array}$} & A & 3.10 & 0.40 & \multirow[t]{4}{*}{$1.3 \times 10^{-12}$} & \\
\hline & B & 3.00 & 0.61 & & \\
\hline & $\mathrm{C}$ & 4.77 & 1.74 & & \\
\hline & $\mathrm{D}$ & 4.02 & 1.16 & & \\
\hline
\end{tabular}

${ }^{a}$ The channular diffusivity is calculated as $D=l^{2} k$, where $l$ is the jump length and $k$ is the total rate constant that is calculated from $k_{\text {tot }}^{-1}=$ $\sum_{n=1}^{N} k_{n}^{-1} \sigma_{n}$, where $N$ is the number of jumps a $\mathrm{Li}$ ion/hole needs to perform in order to move in the $c$-direction, that is, $N=2$ (A or B), $k_{n}=\nu \mathrm{e}^{-E_{\text {act }, n} / k_{\mathrm{B}} T}$ is the rate constant for an elementary jump (that is, A or B), where $\nu=10^{13} \mathrm{~s}^{-1}$ is a typical prefactor, $E_{\text {act }, n}$ is the activation barrier for the $n^{\text {th }}$ elementary jump, $k_{\mathrm{B}}$ is Boltzmann's constant, and $T$ is the absolute temperature, which is here taken to be room temperature, and $\sigma_{n}$ is a symmetry factor, which in the present case is unity. ${ }^{b}$ Diffusivity is for $\mathrm{Li}$ concentration below 0.5 (private communication with Cambaz et al. ${ }^{31}$ ).

should be noted, that a $+U$ correction will tend to penalize the movement of the diffusing species at the transition state of the migration process and thereby result in a possible overestimation of the activation barrier. Whereas the DFT barriers of Seo et al. ${ }^{8}$ might be taken as a lower bound of the true activation barriers, the DFT $+U$-calculated barriers presented in this study serve as an upper bound on the true activation barriers. However, we point out that our calculated Li-ion diffusion coefficient of $5.6 \times 10^{-15} \mathrm{~cm}^{2} / \mathrm{s}$ agrees well with the experimental value of $5.63 \times 10^{-14} \mathrm{~cm}^{2} / \mathrm{s}$ measured by Cambaz et al. ${ }^{31}$ using cyclic voltammetry, motivating our use of the Hubbard- $U$ correction. Despite the aforementioned barrier discrepancy, the ordering of the barriers, that is, $E_{\mathrm{b}}{ }^{\mathrm{A}}<E_{\mathrm{b}}{ }^{\mathrm{B}}$, is consistent with the results of Seo et al. ${ }^{8}$ even with the commensurate modulation included.

The calculations above, summarized in Table 1 , show that the transport of $\mathrm{Li}$ ions and holes in bulk $\mathrm{Li}_{x} \mathrm{FeBO}_{3}$ occurs predominantly along the $c$-axis in nonlinear channels, constituted by corner-sharing $\mathrm{LiO}_{4}$ complexes. Only two distinct types of jumps are needed for macroscopic transport, and the $\mathrm{A}$ and $\mathrm{B}$ jumps will thus dominate the macroscopic diffusion.

3.4. Ionic Transport in $\mathrm{Li}_{0.5} \mathrm{FeBO}_{3}$. In order to obtain the kinetic barriers for $\mathrm{Li}$ diffusion in the half-lithiated phase, the energy of a $\mathrm{Li}$ configuration in which the Li-ion motion is constrained to one channel (extending along the $c$-axis) relative to the lowest-energy half-lithiated configuration was mapped out in Figure 5 (indicated by the blue line). In these channels, two $\mathrm{Li}$ ions, $\mathrm{Li}^{1}$ and $\mathrm{Li}^{2}$, move via the combined $\mathrm{A}$ and $\mathrm{B}$ jumps shown in Figure 4: The $\mathrm{Li}^{2}$ jump between configuration $\mathrm{A}$ and $\mathrm{B} 1$ corresponds to an $\mathrm{A}$ jump in the endmembers $\left(\mathrm{FeBO}_{3} /\right.$ $\left.\mathrm{LiFeBO}_{3}\right)$, the $\mathrm{Li}^{1}$ jump from configuration $\mathrm{B} 1$ to $\mathrm{C}$ corresponds to an endmember $\mathrm{B}$ jump, the $\mathrm{Li}^{2}$ jump from configuration $\mathrm{C}$ to $\mathrm{D} 1$ corresponds to an endmember $\mathrm{B}$ jump, the $\mathrm{Li}^{1}$ jump from configuration $\mathrm{D} 1$ to $\mathrm{E}$ corresponds to an endmember $\mathrm{A}$ jump, the $\mathrm{Li}^{2}$ jump from configuration $\mathrm{E}$ to $\mathrm{B} 2$ 


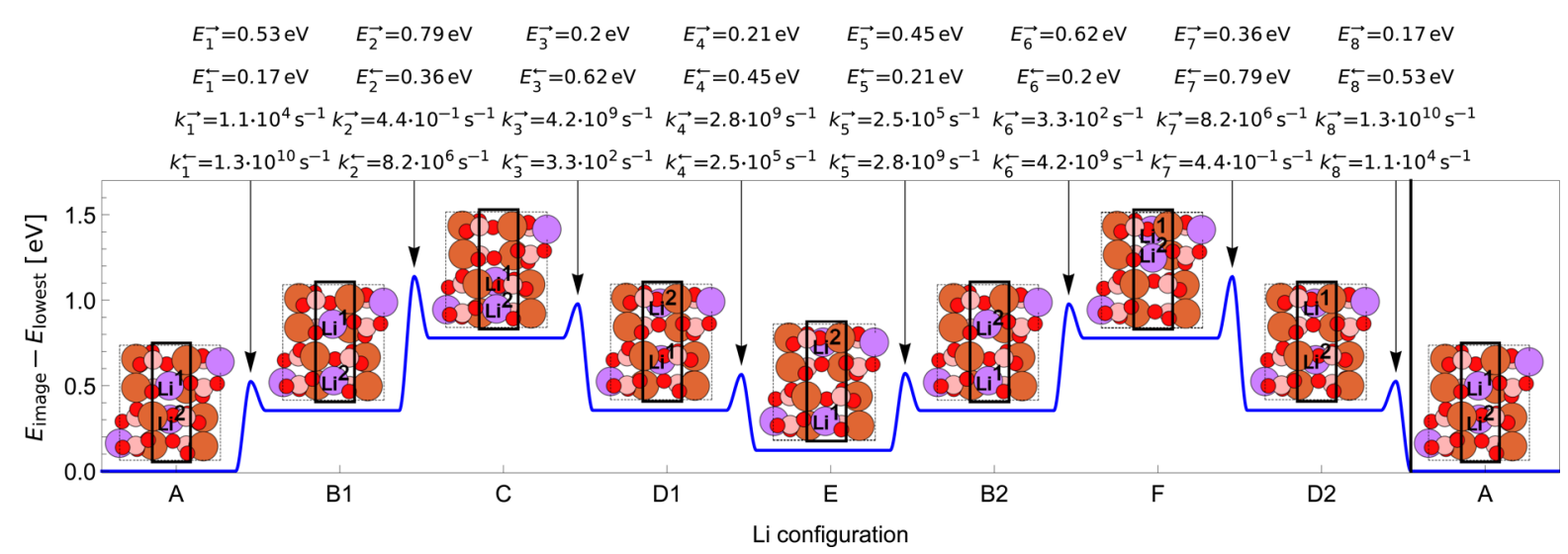

Figure 5. Energy landscape of two $\mathrm{Li}$ ions, $\mathrm{Li}^{1}$ and $\mathrm{Li}^{2}$, diffusing in the channel indicated by the thick black box in $\mathrm{Li}_{0.5} \mathrm{FeBO}_{3}$ simulated in the unit cell shown by the large black box. The kinetic barrier at $E_{\{1, \ldots, 8\}}$ is the maximum barrier of the Li-ion jumps depicted in Figure S2 in Supporting Information, and the associated jump rate, $k_{\{1, \ldots, 8\}}$, is also listed. B1 and B2 have identical Li distributions as do D1 and D2. The vertical line after D2 indicates the end of a full cycle (from A to D2). The coloring of the atoms follows that of Figure 1.

corresponds to an endmember A jump, the $\mathrm{Li}^{1}$ jump from configuration $\mathrm{B} 2$ to $\mathrm{F}$ corresponds to an endmember B jump, the $\mathrm{Li}^{2}$ jump from configuration $\mathrm{F}$ to $\mathrm{D} 2$ corresponds to an endmember $B$ jump, and the $\mathrm{Li}^{1}$ jump from configuration $\mathrm{D} 2$ to A corresponds to an endmember A jump. The smallest $\mathrm{Li}-$ $\mathrm{Li}$ distance in the channel is $3.40 \AA$ in configuration $\mathrm{A}, 5.07 \AA$ in configurations $\mathrm{B} 1, \mathrm{~B} 2, \mathrm{D} 1$, and $\mathrm{D} 2,3.69 \AA$ in configuration $\mathrm{E}$, and $2.98 \AA$ in configurations $\mathrm{C}$ and F. NEB calculations were conducted on jumps between neighboring configurations, and the activation barriers and $\mathrm{Li}$-ion trajectories are shown in Figure S2 in Supporting Information. The activation barriers with the resulting jump rates are listed above each barrier in Figure 5. The barriers $E_{2}^{\rightarrow}$ and $E_{7}^{\leftarrow}$ both of $0.79 \mathrm{eV}$ are slightly higher than the $\mathrm{Li}$-ion barrier in $\mathrm{FeBO}_{3}(0.75 \mathrm{eV})$ because the diffusing $\mathrm{Li}$ ion in each case approaches another $\mathrm{Li}$ ion in the channel (until $\mathrm{Li}-\mathrm{Li}$ distance of $2.98 \AA$ ) and thereby increases its Coulombic repulsion. The diffusivity associated with two $\mathrm{Li}$ ions jumping from $\mathrm{A}$ to $\mathrm{A}$ (that is, with a jump length of $c=$ $10.35 \AA$ ) is $3.3 \times 10^{-26} \mathrm{~cm}^{2} / \mathrm{s}$, which is much lower than the diffusivity associated with $\mathrm{Li}$-ion transport in $\mathrm{FeBO}_{3}(5.6 \times$ $\left.10^{-15} \mathrm{~cm}^{2} / \mathrm{s}\right)$ and Li-hole transport in $\mathrm{LiFeBO}_{3}\left(1.9 \times 10^{-12}\right.$ $\mathrm{cm}^{2} / \mathrm{s}$ ), indicating that the Li diffusion is strongly impeded in the half-lithiated phase.

3.5. The $\mathrm{LiFeBO}_{3}-\mathrm{Li}_{0.5} \mathrm{FeBO}_{3}$ Interface. Our convex-hull analysis in Figure 2 and previous GITT experiments ${ }^{2,15,16}$ suggest that a stable interface between a fully lithiated and halflithiated phase could be formed. During discharge, Li ions from the $\mathrm{Li}_{0.5} \mathrm{FeBO}_{3}$ phase will accumulate at the interface between $\mathrm{LiFeBO}_{3}$ and $\mathrm{Li}_{0.5} \mathrm{FeBO}_{3}$, and in order to determine the effects on the $\mathrm{Li}$ transport at this interface, the $\mathrm{Li}$ diffusion occurring in close vicinity of an interface between $\mathrm{LiFeBO}_{3}$ containing a $\mathrm{Li}$ hole and $\mathrm{Li}_{0.5} \mathrm{FeBO}_{3}$ was investigated through a NEB calculation. The pathway with the associated activation barrier is shown in Figure 6. Also indicated is the energy level of the interface structure in which the $\mathrm{Li}$ hole resides at the interface in the $\mathrm{Li}$-poor region $\left(\mathrm{Li}_{0.5} \mathrm{FeBO}_{3}\right)$, which is about $0.1 \mathrm{eV}$ higher than having the $\mathrm{Li}$ hole in the Li-rich region (green point). The barriers during charge $(0.32 \mathrm{eV})$ and discharge $(0.19 \mathrm{eV})$ are both much lower compared to the diffusion barriers of $\mathrm{Li}$ ions in $\mathrm{FeBO}_{3}$ and $\mathrm{Li}$ holes in $\mathrm{LiFeBO}_{3}$. This is not surprisingly, because $\mathrm{Li}$ diffusion across the $\mathrm{LiFeBO}_{3}-$ $\mathrm{FeBO}_{3}$ interface, found in Figure S3 in Supporting Information, also displayed lower barriers than those for Li-ion/hole in

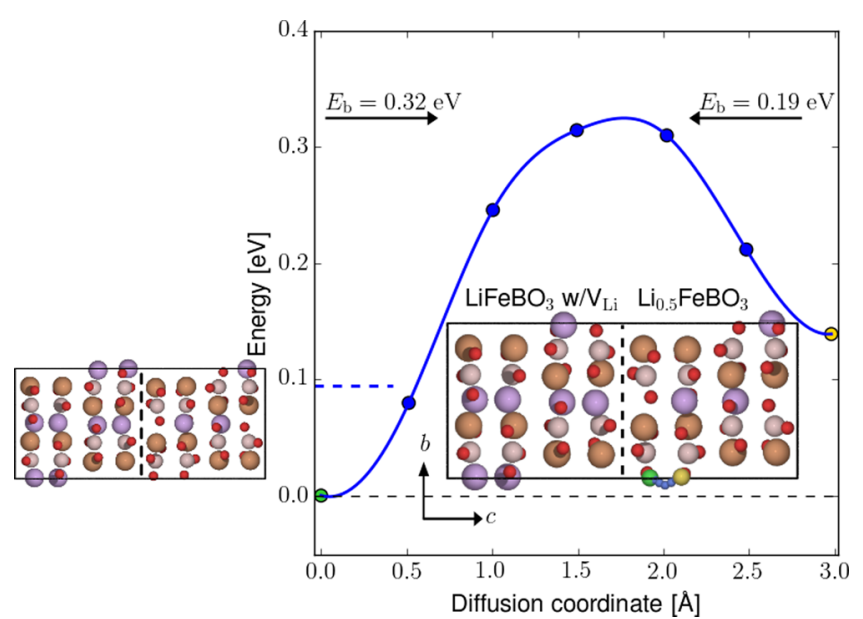

Figure 6. Activation-barrier profile for lithium diffusion in the halflithiated phase (right part of the big inset structure) near the phase boundary between $\mathrm{LiFeBO}_{3}$ containing a $\mathrm{Li}$ hole and $\mathrm{Li}_{0.5} \mathrm{FeBO}_{3}$ indicated by the vertical dashed line in the right inset. The diffusing $\mathrm{Li}$ ion is indicated by green (initial position), blue (intermediate positions) and yellow (final position). The energy of the interface containing the $\mathrm{Li}$ hole in the half-lithiated region (left inset) is indicated by the blue dashed line at $0.1 \mathrm{eV}$. The coloring of the rest of the atoms follows that of Figure 1. As our previous NEB calculations revealed (vide Section 3.3), the Li-hole transport is essentially unaffected by the modulation effects, and the calculations here were therefore performed in a $(a, b, 2 c)$ supercell of unmodulated $\mathrm{LiFeBO}_{3}$ and $\mathrm{Li}_{0.5} \mathrm{FeBO}_{3}$.

$\mathrm{FeBO}_{3} / \mathrm{LiFeBO}_{3}$. Hence, $\mathrm{Li}$ diffusion in the interfacial region between the $\mathrm{LiFeBO}_{3}$ phase containing a $\mathrm{Li}$ hole and the $\mathrm{Li}_{0.5} \mathrm{FeBO}_{3}$ phase is not expected to be impeded due to the interfaces per se.

3.6. Electronic Transport. During discharge of the $\mathrm{Li}_{0.5} \mathrm{FeBO}_{3}$ phase, hole polarons have to traverse a shell of the $\mathrm{LiFeBO}_{3}$ phase in order to recombine with $\mathrm{Li}$ ions being inserted into the $\mathrm{Li}_{0.5} \mathrm{FeBO}_{3}$ core. In the following, investigations of electron-polaron transport in $\mathrm{FeBO}_{3}$ and holepolaron transport in $\mathrm{LiFeBO}_{3}$ have been conducted to determine possible polaronic limitations to the chargedischarge process.

We found that upon adding (removing) an electron to $\mathrm{FeBO}_{3}$ (from modulated $\mathrm{LiFeBO}_{3}$ ), an electron (hole) polaron 
a)

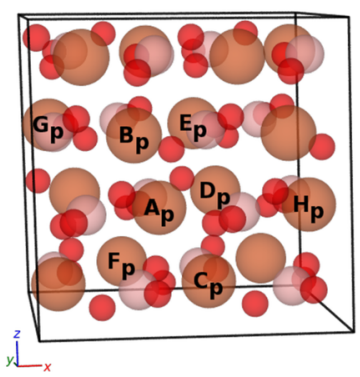

b)

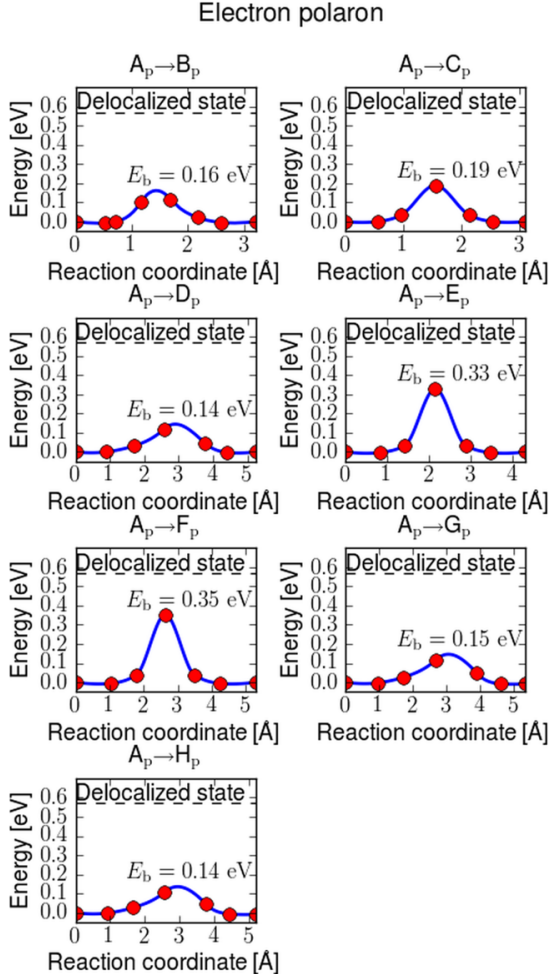

c)

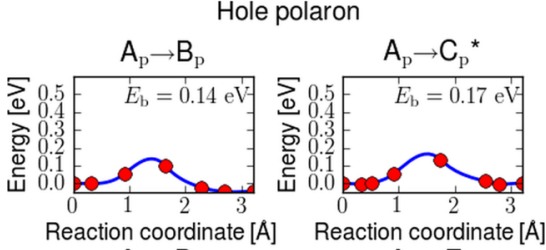

$$
A_{\mathrm{p}} \rightarrow D_{\mathrm{p}}
$$
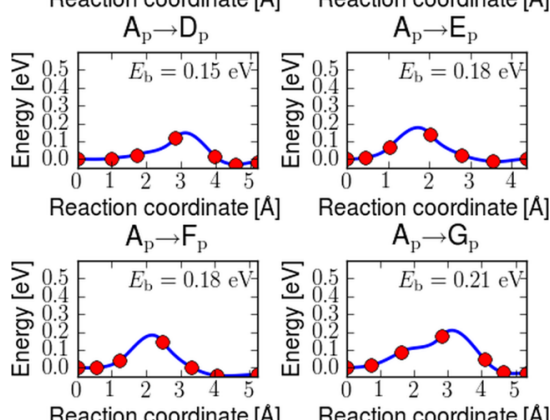

$\mathrm{A}_{\mathrm{p}} \rightarrow \mathrm{G}_{\mathrm{p}}$

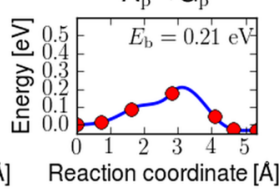

Reaction coordinate

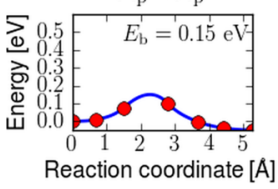

Figure 7. (a) Polaronic hops from Fe site $A_{p}$ to neighboring Fe sites $B_{p}, C_{p}, D_{p}, E_{p}, F_{p}, G_{p}$, and $H_{p}$ with associated activation barriers for hole-polaron hops in $\mathrm{LiFeBO}_{3}$ and (b) electron-polaron hops in $\mathrm{FeBO}_{3}$ (c). ${ }^{*}$ This hole-polaron hop between $\mathrm{A}_{\mathrm{p}}$ and $\mathrm{C}_{\mathrm{p}}$ is that of the unmodulated phase

was localized at an $\mathrm{Fe}^{3+}\left(\mathrm{Fe}^{2+}\right)$ ion, increasing (decreasing) the bond lengths by $0.14 \AA(0.12 \AA)$ and changing the magnetic moment from $4.29 \mu_{\mathrm{B}}\left(3.75 \mu_{\mathrm{B}}\right)$ to $3.79 \mu_{\mathrm{B}}\left(4.27 \mu_{\mathrm{B}}\right)$. According to the Mulliken criterion ${ }^{32}$ calculated magnetic moments of 3.75 and $3.79 \mu_{\mathrm{B}}$ correspond to a nominal magnetic moment of $4 \mu_{\mathrm{B}}$ originating from the unpaired spin counts of the $\mathrm{d}^{6}$ ion $\mathrm{Fe}^{2+}$, and $4.29 \mu_{\mathrm{B}}$ and $4.27 \mu_{\mathrm{B}}$ correspond to a nominal magnetic moment of $5 \mu_{\mathrm{B}}$ originating from the unpaired spin counts of the $\mathrm{d}^{5}$ ion $\mathrm{Fe}^{3+}$. In the lowest-energy configuration of the half-lithiated phase shown in Figure 3, an electron (hole) polaron was found to be more stable than a delocalized electron (hole) by $0.65 \mathrm{eV}(0.47 \mathrm{eV})$. In $\mathrm{Li}_{0.5} \mathrm{FeBO}_{3}$, the polaron-hosting $\mathrm{Fe}$ ion showed the same trends as those in the active endmembers. Upon adding (removing) an electron to $\mathrm{FeBO}_{3}$ (from modulated $\mathrm{LiFeBO}_{3}$ ), an electron (hole) polaron was localized at a neighboring $\mathrm{Fe}^{3+}$ $\left(\mathrm{Fe}^{2+}\right)$ ion, an increase (decrease) in the $\mathrm{Fe}-\mathrm{O}$ bond lengths by $0.13 \AA(0.12 \AA)$ and a moment change from $4.27 \mu_{\mathrm{B}}\left(3.77 \mu_{\mathrm{B}}\right)$ to $3.76 \mu_{\mathrm{B}}\left(4.29 \mu_{\mathrm{B}}\right)$, corresponding to nominal magnetic moment $4 \mu_{\mathrm{B}}\left(5 \mu_{\mathrm{B}}\right)$, was observed, proving the existence of electron and hole polarons in the half-lithiated phase.

In order to determine possible limitations on the electrochemical performance of $\mathrm{Li}_{x} \mathrm{FeBO}_{3}$ originating from effects related to the electronic transport, $\mathrm{NEB}$ calculations of polaron jumps in bulk $\mathrm{FeBO}_{3}$ and $\mathrm{LiFeBO}_{3}$ were conducted for feasible electron- and hole-polaron hops, shown in Figure 7, namely a polaron hop from $F e$ site $A_{p}$ to $F e$ site $B_{p}$ (abbreviated $A_{p}-B_{p}$ ), a polaron hop from $F e$ site $A_{p}$ to Fe site $C_{p}$ (abbreviated $A_{p}-C_{p}$ ), a polaron hop from $F e$ site $A p$ to Fe site $D_{p}$ (abbreviated $A_{p}$ $D_{p}$ ), a polaron hop from Fe site $A_{p}$ to Fe site $E_{p}$ (abbreviated $A_{p}-E_{p}$ ), a polaron hop from Fe site $A_{p}$ to $F e$ site $F_{p}$ (abbreviated $A_{p}-F_{p}$ ), a polaron hop from Fe site $A_{p}$ to Fe site $G_{p}$ (abbreviated $\left.A_{p}-G_{p}\right)$, and a polaron hop from $F e$ site $A_{p}$ to $F e$ site $H_{p}$ (abbreviated $A_{p}-H_{p}$ ) with the associated calculated NEB barriers shown in Figure $7 b, c$. Movement of both electron and hole polarons along the $a$-axis as well as along the $b$-axis is possible via two $A_{p}-D_{p}$ hops with the barrier being $0.15 \mathrm{eV}$ for the hole polaron and $0.14 \mathrm{eV}$ for the electron polaron. The movement of polarons along the $c$-axis is achieved by the combined hopping mechanism of $A_{p}-B_{p}, A_{p}-C_{p}$, and $A_{p}-H_{p}$ with the highest barrier being $0.15 \mathrm{eV}\left(\mathrm{A}_{\mathrm{p}}-\mathrm{H}_{\mathrm{p}}\right.$ hop) for the hole polaron and $0.19 \mathrm{eV}\left(\mathrm{A}_{\mathrm{p}}-\mathrm{C}_{\mathrm{p}}\right.$ hop $)$ for the electron-polaron. All electron-polaron activation barriers are seen to be well below the delocalization energy of $0.57 \mathrm{eV}$ (vide Figure 7) required to delocalize the electron polaron. It was not possible to find a delocalized solution for hole polarons in the modulated phase 
indicating that hole polarons are particularly stable in this phase. Additionally, we have calculated the activation barriers for hole-polaron hopping in unmodulated $\mathrm{LiFeBO}_{3}$ which are shown in Figure S4 in Supporting Information, and by comparing these results with those for the modulated phase in Figure $7 \mathrm{c}$ no significant change in the hole-polaron barriers upon modulation is observed.

Considering the most stable half-lithiated structure in Figure 3 found in the convex-hull analysis of Figure 2 for a hole polaron hopping through this half-lithiated phase, the highest barrier for the lowest-barrier path, $A_{h}-B_{h}-C_{h}-D_{h}-A_{h}^{\prime}$, is $0.21 \mathrm{eV}$ (the $B_{h}-C_{h}$ hop in Figure $3 c$ ). During charge, a hole polaron could still travel through the half-lithiated phase but the barrier is increased to $0.21 \mathrm{eV}$ from the $0.15 \mathrm{eV}$ barrier in the fully delithiated phase (assuming that the polaron barrier of each individual hop does not change significantly upon changing the $\mathrm{Li}$ concentration). Likewise, for an electron polaron propagating in the half-lithiated phase, the highest barrier associated with the lowest-barrier path, $\mathrm{A}_{\mathrm{e}}-\mathrm{B}_{\mathrm{e}}-\mathrm{C}_{\mathrm{e}}-\mathrm{D}_{\mathrm{e}}-\mathrm{A}^{\prime}{ }_{\mathrm{e}}$, is $0.35 \mathrm{eV}$ (the $A_{e}-B_{e}$ hop in Figure 3c). During discharge, an electron polaron could still travel through the half-lithiated phase but the barrier is increased to $0.35 \mathrm{eV}$ from the $0.19 \mathrm{eV}$ barrier in the fully delithiated phase. Hence, the electronic mobility during both charge and discharge is predicted to be lowered in the halflithiated phase (vide Figure 3) compared to the pristine phases.

Bo et al. ${ }^{16}$ experimentally observed an increase in the difference in charge and discharge potentials, giving rise to an overvoltage of more than $0.5 \mathrm{~V}$ at $\mathrm{C} / 30$, during charging of $\mathrm{LiFeBO}_{3}$ to $\mathrm{Li}_{0.5} \mathrm{FeBO}_{3}$ (vide their Figure 1). This can be related to our model in the following way: During charge, a region of $\mathrm{Li}_{0.5} \mathrm{FeBO}_{3}$ will be formed around the $\mathrm{LiFeBO}_{3}$ nanoparticle and due to the higher activation barriers for ionic and polaronic transport in $\mathrm{Li}_{0.5} \mathrm{FeBO}_{3}$ relative to $\mathrm{FeBO}_{3}$ and $\mathrm{LiFeBO}_{3}$, a higher electric field is required to drive the delithiation process, which manifests itself as an increase in the charge-discharge potential difference. During discharge of $\mathrm{Li}_{0.5} \mathrm{FeBO}_{3}$, a $\mathrm{LiFeBO}_{3}$ phase would form around the $\mathrm{Li}_{0.5} \mathrm{FeBO}_{3}$ core, and since the barriers for $\mathrm{Li}$ diffusion in bulk $\mathrm{LiFeBO}_{3}$ and across the $\mathrm{LiFeBO}_{3}-\mathrm{Li}_{0.5} \mathrm{FeBO}_{3}$ interface are relatively low compared to those of $\mathrm{Li}$ diffusion in $\mathrm{Li}_{0.5} \mathrm{FeBO}_{3}$, no significant charge-discharge difference related to $\mathrm{Li}$ diffusion is expected to occur. This is supported by the charge-discharge data in Figure 1 in Bo et al. ${ }^{16}$ as the chargedischarge potential difference is observed to decrease during discharge.

The intrinsically poor conduction of both $\mathrm{Li}$ ions and electron/hole polarons in the most stable intermediate phase, $\mathrm{Li}_{0.5} \mathrm{FeBO}_{3}$, might not be restricted to $\mathrm{LiFeBO}_{3}$ but could also exist in other lithiated transition-metal borate, such as those containing $\mathrm{Mn}$ and $\mathrm{Co}$ as these are also suggested to have their lithium diffusion kinetically limited. ${ }^{33}$ The phase-stability analysis and path techniques employed in the present work could be used to explain whether these Li-electrode materials suffer from the same fundamental limitations as the $\mathrm{LiFeBO}_{3}$ electrode. Besides down-sizing the $\mathrm{LiFeBO}_{3}$ nanoparticles to decrease the diffusion path length, recent studies ${ }^{34,35}$ have shown that substitution of $\mathrm{Fe}$ by other transition metals could improve the poor transport properties of $\mathrm{LiFeBO}_{3}$.

\section{CONCLUSIONS}

In this work, the structural and kinetic properties of $\mathrm{Li}_{x} \mathrm{FeBO}_{3}$ were investigated using Hubbard-corrected DFT, including the effects from the previously reported commensurate modulation of $\mathrm{LiFeBO}_{3}$. A thermodynamic phase-stability analysis revealed a particularly stable half-lithiated phase together with a relatively stable $\mathrm{Li}_{0.75} \mathrm{FeBO}_{3}$ phase, whereas the $\mathrm{Li}_{0.875} \mathrm{FeBO}_{3}$ phase predicted to be stable by Yamada et al. ${ }^{2}$ was not found to be stable in our study. Our barriers for Li-ion and hole transport in bulk $\mathrm{Li}_{x} \mathrm{FeBO}_{3}$ phases indicated highly anisotropic Li-ion motion with the lowest-barrier pathway being along the $c$-axis with an associated diffusivity of $5.6 \times 10^{-15} \mathrm{~cm}^{2} / \mathrm{s}$ for Liion diffusion in good agreement with experiments $\left(5.6 \times 10^{-14}\right.$ $\mathrm{cm}^{2} / \mathrm{s}$ ). It was shown that the $\mathrm{Li}$ diffusion in the bulk of $\mathrm{Li}_{0.5} \mathrm{FeBO}_{3}$ limited the overall $\mathrm{Li}$ diffusion in the active material. Electronic conduction was shown to be mediated by small electron and hole polarons with relatively low hopping barriers in $\mathrm{FeBO}_{3}$ and $\mathrm{LiFeBO}_{3}$ but relatively high hopping barriers in $\mathrm{Li}_{0.5} \mathrm{FeBO}_{3}$. This barrier increase lowers the mobility of the polarons as they enter the half-lithiated phase. On the contrary, the $\mathrm{Li}$ diffusion in the vicinity of an interface between $\mathrm{LiFeBO}_{3}$ containing a hole and $\mathrm{Li}_{0.5} \mathrm{FeBO}_{3}$ during charge/discharge is not expected to reduce the overall $\mathrm{Li}$-ion/hole diffusion in $\mathrm{Li}_{x} \mathrm{FeBO}_{3}$, because the associated kinetic barriers are lower than those associated with $\mathrm{Li}$-ion/hole diffusion in the delithiated/ lithiated phases. Interestingly, the barriers for Li-hole diffusion and hole-polaron hopping in the modulated phase were found to the same as those in the unmodulated phase. Hence, in the transport model presented here the combined intrinsic reduction of $\mathrm{Li}$-ion and electron/hole-polaron mobility in bulk $\mathrm{Li}_{0.5} \mathrm{FeBO}_{3}$ relative to $\mathrm{LiFeBO}_{3}$ and $\mathrm{FeBO}_{3}$ could explain the experimentally reported large overvoltage at initial-stage delithiation of $\mathrm{LiFeBO}_{3}$. Remedies for these transport-related issues might be found in decreasing the size of the $\mathrm{LiFeBO}_{3}$ particles and substituting some of the $\mathrm{Fe}$ atoms by other cations. ${ }^{34}$ Work along this line is now underway.

\section{ASSOCIATED CONTENT}

\section{Supporting Information}

The Supporting Information is available free of charge on the ACS Publications website at DOI: 10.1021/acs.jpcc.6b03456.

Fractional coordinates of the $\mathrm{Li}$ atoms in the most stable configuration of $\mathrm{Li}_{0.5} \mathrm{FeBO}_{3}$, NEB-calculated activation barriers for Li-hole diffusion in unmodulated $\mathrm{LiFeBO}_{3}$, NEB-calculated activation barriers for diffusion of $\mathrm{Li}$ ions in half-lithiated phases, results on calculations of transport across the $\mathrm{LiFeBO}_{3}-\mathrm{FeBO}_{3}$ interface and NEB-calculated activation barriers for hole-polaron hopping in unmodulated $\mathrm{LiFeBO}_{3}$ (PDF)

\section{AUTHOR INFORMATION}

\section{Corresponding Author}

*E-mail: teve@dtu.dk. Tel: +45 51641787.

\section{Notes}

The authors declare no competing financial interest.

\section{ACKNOWLEDGMENTS}

The research leading to these results has received funding from the European Union's Seventh Framework Programme (FP7/ 2007-2013) under Grant 608575. J.M.G.L. acknowledges support from the Spanish Ministry of Economy and Competitiveness under Projects FIS2012-30996 and FIS201346159-C3-1-P and from the Villum Foundation's Young Investigator Programme (4th round, project: In silico design of efficient materials for next generation batteries. Grant 10096). 


\section{REFERENCES}

(1) Yabuuchi, N.; Ohzuku, T. Novel Lithium Insertion Material of $\mathrm{LiCo}_{1 / 3} \mathrm{Ni}_{1 / 3} \mathrm{Mn}_{1 / 3} \mathrm{O}_{2}$ for Advanced Lithium-Ion Batteries. J. Power Sources 2003, 119-121, 171-174.

(2) Yamada, A.; Iwane, N.; Harada, Y.; Nishimura, S.; Koyama, Y.; Tanaka, I. Lithium Iron Borates as High-Capacity Battery Electrodes. Adv. Mater. 2010, 22 (32), 3583-3587.

(3) Park, M.; Zhang, X.; Chung, M.; Less, G. B.; Sastry, A. M. A Review of Conduction Phenomena in Li-Ion Batteries. J. Power Sources 2010, 195 (24), 7904-7929.

(4) Hohenberg, P.; Kohn, W. Inhomogeneous Electron Gas. Phys. Rev. 1964, 136 (3B), B864-B871.

(5) Kohn, W.; Sham, L. J. Phys. Rev. 1965, 140 (4A), A1133-A1138.

(6) Ceder, G.; Persson, K. How Supercomputers Will Yield a Golden Age of Materials Science. Sci. Am. 2013, 309, 36-40.

(7) Morgan, D.; Van der Ven, A.; Ceder, G. Li Conductivity in $\mathrm{Li}_{x} \mathrm{MPO}_{4}(\mathrm{M}=\mathrm{Mn}, \mathrm{Fe}, \mathrm{Co}, \mathrm{Ni})$ Olivine Materials. Electrochem. SolidState Lett. 2004, 7 (2), A30-A32.

(8) Seo, D.-H.; Park, Y.-U.; Kim, S.-W.; Park, I.; Shakoor, R.; Kang, K. First-Principles Study on Lithium Metal Borate Cathodes for Lithium Rechargeable Batteries. Phys. Rev. B: Condens. Matter Mater. Phys. 2011, 83 (20), 205127-8.

(9) Ong, S. P.; Chevrier, V. L.; Ceder, G. Comparison of Small Polaron Migration and Phase Separation in Olivine $\mathrm{LiMnPO}_{4}$ and $\mathrm{LiFePO}_{4}$ Using Hybrid Density Functional Theory. Phys. Rev. B: Condens. Matter Mater. Phys. 2011, 83 (7), 0751121-0751127.

(10) Ong, S. P.; Mo, Y.; Ceder, G. Low Hole Polaron Migration Barrier in Lithium Peroxide. Phys. Rev. B: Condens. Matter Mater. Phys. 2012, 85 (8), 2-5.

(11) Garcia-Lastra, J. M.; Myrdal, J. S. G.; Christensen, R.; Thygesen, K. S.; Vegge, T. DFT $+U$ Study of Polaronic Conduction in $\mathrm{Li}_{2} \mathrm{O}_{2}$ and $\mathrm{Li}_{2} \mathrm{CO}_{3}$ : Implications for Li-air Batteries. J. Phys. Chem. C 2013, 117 (11), 5568-5577.

(12) Mekonnen, Y. S.; Garcia-Lastra, J. M.; Hummelshøj, J. S.; Jin, C.; Vegge, T. Role of $\mathrm{Li}_{2} \mathrm{O}_{2} @ \mathrm{Li}_{2} \mathrm{CO}_{3}$ Interfaces on Charge Transport in Nonaqueous Li-Air Batteries. J. Phys. Chem. C 2015, 119 (32), 18066-18073.

(13) Churikov, A. V.; Ivanishchev, A. V.; Ivanishcheva, I. A.; Sycheva, V. O.; Khasanova, N. R.; Antipov, E. V. Determination of Lithium Diffusion Coefficient in $\mathrm{LiFePO}_{4}$ Electrode by Galvanostatic and Potentiostatic Intermittent Titration Techniques. Electrochim. Acta 2010, 55 (8), 2939-2950.

(14) Ouyang, C.; Shi, S.; Wang, Z.; Huang, X.; Chen, L. FirstPrinciples Study of Li Ion Diffusion in $\mathrm{LiFePO}_{4}$. Phys. Rev. B: Condens. Matter Mater. Phys. 2004, 69 (10), 104303.

(15) Bo, S.-H.; Wang, F.; Janssen, Y.; Zeng, D.; Nam, K.-W.; Xu, W.; Du, L.-S.; Graetz, J.; Yang, X.-Q.; Zhu, Y.; Parise, J. B.; Grey, C. P.; Khalifah, P. G. Degradation and (De)lithiation Processes in the High Capacity Battery Material $\mathrm{LiFeBO}_{3}$. J. Mater. Chem. 2012, 22 (18), 8799-8809.

(16) Bo, S. H.; Nam, K. W.; Borkiewicz, O. J.; Hu, Y. Y.; Yang, X. Q.; Chupas, P. J.; Chapman, K. W.; Wu, L.; Zhang, L.; Wang, F.; Grey, C. P.; Khalifah, P. G. Structures of Delithiated and Degraded $\mathrm{LiFeBO}_{3}$, and Their Distinct Changes upon Electrochemical Cycling. Inorg. Chem. 2014, 53 (13), 6585-6595.

(17) Legagneur, V.; An, Y.; Mosbah, A.; Portal, R.; Le Gal La Salle, A.; Verbaere, A.; Guyomard, D.; Piffard, Y. $\mathrm{LiMBO}_{3}(\mathrm{M}=\mathrm{Mn}, \mathrm{Fe}$, Co): Synthesis, Crystal Structure and Lithium Deinsertion/insertion Properties. Solid State Ionics 2001, 139 (1-2), 37-46.

(18) Janssen, Y.; Middlemiss, D. S.; Bo, S. H.; Grey, C. P.; Khalifah, P. G. Structural Modulation in the High Capacity Battery Cathode Material $\mathrm{LiFeBO}_{3}$. J. Am. Chem. Soc. 2012, 134 (30), 12516-12527.

(19) Momma, K.; Izumi, F. VESTA 3 for Three-Dimensional Visualization of Crystal, Volumetric and Morphology Data. J. Appl. Crystallogr. 2011, 44 (6), 1272-1276.

(20) Bahn, S. R; Jacobsen, K. W. An Object-Oriented Scripting Interface to a Legacy Electronic Structure Code. Comput. Sci. Eng. 2002, 4 (3), 56-66.
(21) Kresse, G.; Furthmöller, J. Efficiency of Ab-Initio Total Energy Calculations for Metals and Semiconductors Using a Plane-Wave Basis Set. Comput. Mater. Sci. 1996, 6 (1), 15-50.

(22) Blöchl, P. E. Projector Augmented-Wave Method. Phys. Rev. B: Condens. Matter Mater. Phys. 1994, 50 (24), 17953-17979.

(23) Perdew, J. P.; Burke, K.; Ernzerhof, M. Generalized Gradient Approximation Made Simple. Phys. Rev. Lett. 1996, 77 (18), 38653868.

(24) Blöchl, P. E.; Jepsen, O.; Andersen, O. K. Improved Tetrahedron Method for Brillouin-Zone Integrations. Phys. Rev. B: Condens. Matter Mater. Phys. 1994, 49 (23), 16223-16233.

(25) Islam, M. S.; Fisher, C. A. J. Lithium and Sodium Battery Cathode Materials: Computational Insights into Voltage, Diffusion and Nanostructural Properties. Chem. Soc. Rev. 2014, 43 (1), 185-204.

(26) Meng, Y. S.; Arroyo-de Dompablo, M. E. First Principles Computational Materials Design for Energy Storage Materials in Lithium Ion Batteries. Energy Environ. Sci. 2009, 2 (6), 589.

(27) Anisimov, V. I.; Aryasetiawan, F.; Lichtenstein, I. First-Principles Calculations of the Electronic Structure and Spectra of Strongly Correlated Systems: The LDA+U Method. J. Phys.: Condens. Matter 1997, 9 (997), 767-808.

(28) Monkhorst, H. J.; Pack, J. D. Special Points for Brillouin-Zone Integrations. Phys. Rev. B 1976, 13 (12), 5188-5192.

(29) Bitzek, E.; Koskinen, P.; Gähler, F.; Moseler, M.; Gumbsch, P. Structural Relaxation Made Simple. Phys. Rev. Lett. 2006, 97 (17), 1-4.

(30) Jónsson, H.; Mills, G.; Jacobsen, K. W. Nudged Elastic Band Method for Finding Minimum Energy Paths of Transitions. Class. Quantum Dyn. Condens. Phase Simulations - Proc. Int. Sch. Phys. 1997, 385-404.

(31) Cambaz, M. A.; Anji Reddy, M.; Vinayan, B. P.; Witte, R.; Pohl, A.; Mu, X.; Chakravadhanula, V. S. K.; Kübel, C.; Fichtner, M. Mechanical Milling Assisted Synthesis and Electrochemical Performance of High Capacity $\mathrm{LiFeBO}_{3}$ for Lithium Batteries. ACS Appl. Mater. Interfaces 2016, 8 (3), 2166-2172.

(32) Mulliken, R. S. Electronic Population Analysis on LCAO-MO Molecular Wave Functions. I. J. Chem. Phys. 1955, 23 (10), 18331840.

(33) Masquelier, C.; Croguennec, L. Polyanionic (Phosphates, Silicates, Sulfates) Frameworks as Electrode Materials for Rechargeable Li (or Na) Batteries. Chem. Rev. 2013, 113 (8), 6552-6591.

(34) Kim, J. C.; Seo, D.-H.; Ceder, G. Theoretical Capacity Achieved in a $\mathrm{LiMn}_{0.5} \mathrm{Fe}_{0.4} \mathrm{Mg}_{0.1} \mathrm{BO}_{3}$ Cathode by Using Topological Disorder. Energy Environ. Sci. 2015, 8 (6), 1790-1798.

(35) Li, A.; Xu, L.; Li, C.; Qian, Y. Q. Mesh-like $\mathrm{LiZnBO}_{3} / \mathrm{C}$ Composites as a Prominent Stable Anode for Lithium Ion Rechargeable Batteries. J. Mater. Chem. A 2016, 4, 5489-5494. 